Research Article

\title{
Effects of Hybrid Graphene Oxide with Multiwalled Carbon Nanotubes and Nanoclay on the Mechanical Properties and Fire Resistance of Epoxy Nanocomposite
}

\author{
Tuan Anh Nguyen $(\mathbb{D})$ and Thi Thu Trang Bui \\ Faculty of Chemical Technology, Hanoi University of Industry (HaUI), No. 298, Cau Dien Street, Bac Tu Liem District, \\ Hanoi, Vietnam \\ Correspondence should be addressed to Tuan Anh Nguyen; anhnt@haui.edu.vn
}

Received 16 May 2021; Revised 28 July 2021; Accepted 13 October 2021; Published 9 November 2021

Academic Editor: Zafar Iqbal

Copyright (C) 2021 Tuan Anh Nguyen and Thi Thu Trang Bui. This is an open access article distributed under the Creative Commons Attribution License, which permits unrestricted use, distribution, and reproduction in any medium, provided the original work is properly cited.

\begin{abstract}
In this study, nanoclay I.30E and multiwalled carbon nanotubes (MWCNT) were hybridized with graphene oxide (GO) on Epikote 240 epoxy resin. Research results show that the hybridization between $0.5 \mathrm{wt} . \%$ GO with 1 or 3 wt.\% nanoclay and 0.05 wt.\% MWCNT has better mechanical properties and flame-retardant properties than the component materials. The combination of epoxy nanocomposite materials with flame-retardant additives such as nanoclay, MWCNT, and GO leads to improving flame-retardant and mechanical properties. Flame-retardant materials have no environmental problems and are nontoxic. Therefore, the flame-retardant additives studied in this work have great potential to become one of the promising flame-retardant hybrid materials. The study also showed that the result of the combination, the hybridization between the three components (nanoclay, MWCNT, and GO) synergized the mechanisms of fire resistance, creating insulating barriers, preventing objects from entering material exposed to heat and oxygen in the air.
\end{abstract}

\section{Introduction}

Flame retardants, a large group of polymeric additives, play an important role in improving the fire resistance of polymeric materials. Flame retardants are mainly based on halogens (bromine and chlorine), phosphorus, and inorganic and melamine compounds [1]. To date, many studies have focused on nanoclay, carbon nanotubes [2-4], fly ash [5, 6], graphene oxide [7-11], etc. In addition, a number of works have studied the combination of nanoclay with MWCNTs; nanoclay with fly ash, or MWCNT with fly ash [12]. These works all concluded that the combination of additives provides fire-retardant properties and mechanical properties at a higher threshold when considered separately.

Many studies have been reported on hybrid filler technology in polymers, based on GO and MWCNT [13-16]. The results of this study open up many directions for further research on GO. The results of the studies indicated that very little GO loading also improved the mechanical strength of epoxy composites. Keloth Paduvilan et al. confirmed in their work that the combined effect of graphene oxide and nanoclay can induce a hybrid effect in reducing the air permeability for chlorobutyl-natural rubber blend [16]. The organic hybrid montmorillonite-graphene-filled composite exhibits better thermal stability than pure epoxy. However, if the concentration of hybrid particles is low, the fabricated material has slightly worse properties than the composite material incorporating only graphene oxide [17].

The synergies of graphene nanoplatelets (GP) and montmorillonite nanoclay (MMT) were also reported by Nuruddin et al. The results show that a combination of $3 \mathrm{wt} . \%$ MMT and 0.1 wt.\% GP leads to increased flexural strength and modulus [18]. A laboratory-synthesized graphene oxide (GO) was used as a dispersant for nanoclay (NC) in epoxyphenolic. Different weight ratios of GO/NC when granules are mixed are prepared. They are used in concentrations of $1 \%$ by weight. Graphene oxide itself is capable of acting as a dispersant for other thin particles such as nanoclay; this 
combination gives mechanical properties that tend to increase [19]. GO is a material that holds great promise in the future. Gauvin et al. have studied with only $0.5 \mathrm{wt} . \%$ GO $(<1 \%)$; GO significantly increases the mechanical and thermomechanical properties of vinylester polymers [20, 21]. In this study, the presence of nanoclay hybrid with MWCNT and GO at different filler loads was investigated in relation to mechanical properties and flame retardancy. First, the hybrid nanocomposite was prepared by dispersing nanoclay and MWCNT with a solution of mechanical stirring and ultrasonic vibration into the epoxy resin. The hybrid material is then evaluated through the mechanical strength, using the flame-retardant property measurement method (LOI, UL94).

\section{Materials and Methods}

2.1. Materials. MWCNTs with a diameter of $40-45 \mathrm{~nm}$ and a length of around $3 \mu \mathrm{m}$ were provided by Showa Denko Japan Co. Epikote 240 epoxy (E 240) from bisphenol F was from Shell Chemicals (USA) with $24.6 \%$ epoxy content, equivalent of epoxy group $185-196$, and viscosity at $25^{\circ} \mathrm{C}$ : $0.7 \div 1.1 \mathrm{~Pa} \cdot \mathrm{s}$. Diethylenetriamin (DETA) was from Dow Chemicals (USA); the chemical formula of DETA is as follows: $\mathrm{H}_{2} \mathrm{~N}\left(\mathrm{CH}_{2}\right) \mathrm{NH}\left(\mathrm{CH}_{2}\right)_{2} \mathrm{NH}_{2}, \mathrm{MW}: 103 \mathrm{~g} \cdot \mathrm{mol}^{-1}$, and specific gravity at $25^{\circ} \mathrm{C}: 0.95 \mathrm{~g} / \mathrm{cm}^{3}$. Nanoclay I.30E was from Nanocor (USA): ivory white powder, specific gravity $1.7 \mathrm{~g} / \mathrm{cm}^{3}$, denatured by octadecyl amine.

\subsection{Methods}

2.2.1. Sample Preparation. The content of substances used is as shown in Table 1.

The fabrication of hybrid nanocomposites has been carried out as follows. Initially, Epikote 240 epoxy resin was heated in an oven at 80 degrees $\mathrm{C}$ for 60 minutes; nanoclay I.30E was dried in an oven at $80^{\circ} \mathrm{C}$ for 3 hours. The content of nanoclay I.30E used was $1 \%, 3 \%$, and 5 wt.\% of the mixture; MWCNT used was $0.05 \%$ mass of the mixture. In that gas, the amount of GO used was $0.5 \mathrm{wt} . \%$ of the mixture. The mixture was mechanically stirred at $1000 \mathrm{rpm}$ at 80 degrees Celsius for 3 hours on mechanical stirrer HS-T SET (WiseStir, Korea). Then, the mixture was sonicated in an Elmasonic $\mathrm{S} 300 \mathrm{H}$ (Elma company, Germany) ultrasonic bath (ultrasonic frequency $37 \mathrm{kHz}$, ultrasonic power $300 \mathrm{~W}$ ) at room temperature for 6 hours. Samples were allowed to cool at room temperature; then, DETA curing agent was added, stirred at $150 \mathrm{rpm}$ for 10 minutes, then defoamed for 30 minutes, and samples were poured to determine mechanical properties and anticorrosion properties, burned on stainless steel molds, and, after 24 hours, dried at 80 degrees Celsius for 3 hours, for 7 days to stabilize; mechanical properties and fire retardant were tested.

2.2.2. Analysis. The fire-retardant evaluation methods are as follows:

(i) Limiting Oxygen Index (LOI) according to JIS K720 standard (Japan): the sample bars used for the test were $150 \times 6.5 \times 3 \mathrm{~mm}^{3}$
TABLE 1: Hybrid nanocomposite label according to nanocontent.

\begin{tabular}{lccc}
\hline Label & $\begin{array}{c}\text { Nanoclay \% } \\
\text { (wt.\%) }\end{array}$ & $\begin{array}{c}\text { MWCNT \% } \\
\text { (wt.\%) }\end{array}$ & $\begin{array}{c}\text { GO \% } \\
\text { (wt.\%) }\end{array}$ \\
\hline Neat epoxy & 0 & 0 & 0 \\
1NM0.005MT0.5GO & 1 & 0.05 & 0.5 \\
3NM0.005MT0.5GO & 3 & 0.05 & 0.5 \\
5NM0.005MT0.5GO & 5 & 0.05 & 0.5 \\
\hline
\end{tabular}

(ii) The horizontal burning tests (UL-94HB): standard bar specimens are to be $125 \pm 5 \mathrm{~mm}$ long by $13.0 \pm$ $0.5 \mathrm{~mm}$ wide and provided in the minimum thickness and $3.0(-0.0+0.2)$ mm thick. (ASTM D635-12)

(iii) Vertical burning test: UL $94 \mathrm{~V}$, the standard bar samples shall be $125 \pm 5 \mathrm{~mm}$ long $\times 13.0 \pm 0.5 \mathrm{~mm}$ wide and supplied in the minimum and maximum thicknesses. The maximum thickness does not exceed $13 \mathrm{~mm}$ (ASTM D635-12)

The UL 94 flame-retardant and oxygen limit tests are conducted at the Polymer Materials Research Center, Hanoi University of Technology, Vietnam.

The methods for determining mechanical properties are as follows:

(i) Tensile strength was determined according to ISO $527-1993$ standard on INSTRON $5582-100 \mathrm{kN}$ machine (USA) with tensile speed $5 \mathrm{~mm} / \mathrm{min}$, temperature $25^{\circ} \mathrm{C}$, and humidity $75 \%$

(ii) Bending strength was determined according to ISO 178-1993 standard on INSTRON $5582-100 \mathrm{kN}$ machine (USA) with bending speed $5 \mathrm{~mm} / \mathrm{min}$, temperature $25^{\circ} \mathrm{C}$, and humidity $75 \%$

(iii) Compressive strength was determined according to ISO 604-1993 standard on INSTRON $5582-100 \mathrm{kN}$ machine (USA), compression speed $5 \mathrm{~mm} / \mathrm{min}$, and temperature $25^{\circ} \mathrm{C}$

(iv) Izod impact strength was determined according to ASTM D265 standard on Tinius Olsen machine (USA). Measured at Research Center for Polymer Materials, Hanoi University of Science and Technology

(v) The morphology of the samples was carried out by a scanning electron microscope (SEM, S4800, Japan).

(vi) Fourier transform infrared spectrum (FTIR) is recorded using FTS 2000 FTIR (Varian) using KBr tablets which are created by compressing $\mathrm{KBr}$ powder mixed with a small amount of sample GO

\section{Results and Discussion}

3.1. Mechanical Properties. The results of studying the mechanical properties (tensile strength, flexural strength, compressive strength, and impact strength) of hybrid materials by nanoclay/MWCNT/GO on epoxy resin are 

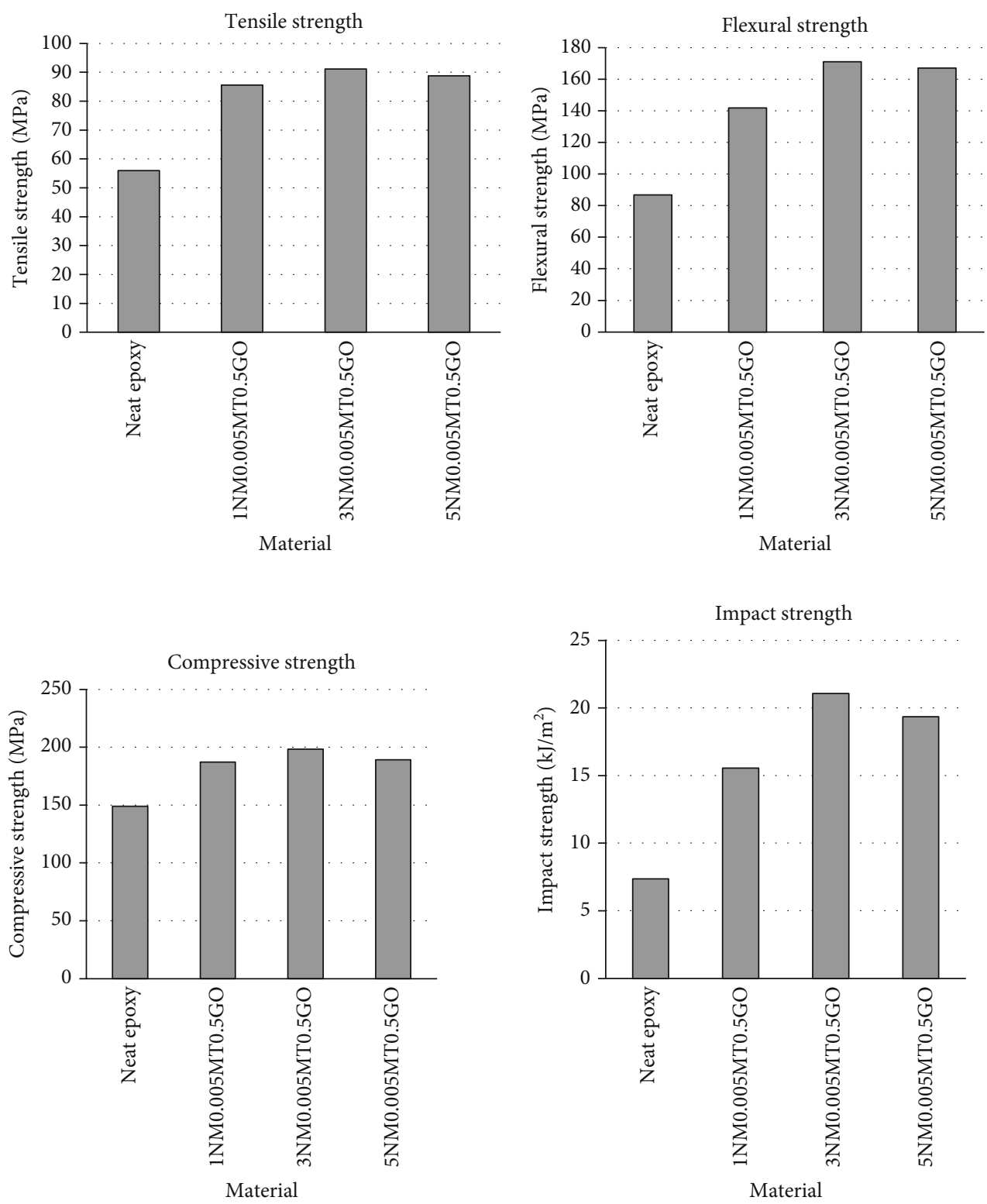

FIgURE 1: Mechanical properties of epoxy composite materials.

presented in Figure 1. From the results of Figure 1, it can be seen that the cross between $3 \mathrm{wt} . \%$ nanoclay, $0.05 \mathrm{wt} . \%$ MWCNT, and 0.5 wt.\% GO gives the best results compared to other combinations.

It can be concluded that the hybridization of the three components (nanoclay, MWCNT, and GO) promoted the interaction between the polymer and the filler. The ratio of hybridization on the elements achieved the best compatibility that was found in this work. Simultaneous addition of three reinforcers enhanced the interface between the dispersed phases and the epoxy resin, thereby promoting transfer from the resin matrix to the reinforcements. Hybrid 3 wt.\% nanoclay with 0.05 wt.\% MWCNT and 0.5 wt.\% GO has $63 \%$ increase in tensile strength, $97.19 \%$ increase in flexural strength, $33.23 \%$ increase in compressive strength, and $163.12 \%$ increase in impact strength compared to epoxy polymers. These results indicate that at the simultaneous addition of nanoclay, MWCNT, and GO at suitable hybridization rates, the material achieves a special structure with a compatibility on the interface between the matrix resin phase and the reinforcements at low level and senior level. It is recognized that when nanoparticles are added, the functional groups present on their surface interact with the epoxy polymer molecules to form strong covalent bonds that enhance their properties such as tensile strength, flexural strength, and hardness. The increase in tensile, flexural, and impact strength is higher as a result of the limitations in molecular chain motion caused by the increased crosslinking of polymers, this increase being moderate enough to prevent the material from hardening to lead to embrittlement. This also causes a reduction in deformation leading to failure [14]. 
3.2. Fire-Retardant Property. The effects of $\mathrm{GO}$ and MWCNTs/nanoclay on LOI values are shown in Figure 2.

From the results of Figure 2, it shows that the hybrid materials at different combination ratios give good fire resistance (limited oxygen index reaches from 27.6 to $31 \%$ of the minimum oxygen for the material to ignite). The flame-retardant mechanism of the hybrid material here can be proposed as the nanoclays, MWCNT, and GO synergistically create thicker-than-normal shields (walls) that prevent the material from coming into contact with source of heat and oxygen in the air.

The flame-retardant mechanism of the hybrid material here can be proposed as follows: the nanolayers, MWCNT, and GO synergistically create thicker-than-normal shields (walls) to prevent the material from being exposed to heat and oxygen sources in the air.

On the other hand, in the presence of GO, GO increases the density, reducing the ability of gas to penetrate from the outside and vice versa or in other words, making the path of gas from the outside to the inside of the material longer due to the road which is longer and more complicated [17].

However, when increasing the nanoclay content to $5 \mathrm{wt} . \%$, the degree of flame retardancy tends to decrease where it can be explained that when the content increased to $5 \mathrm{wt} . \%$ increased defects, the surface interface between reinforcements and epoxy was not the same as before.

Flame-retardant properties were further evaluated by the UL $94 \mathrm{~V}$ method; the results are presented in Table 2. From the results in Table 2, it is again confirmed that the hybrid material by $3 \mathrm{wt} . \%$ nanoclay and $0.05 \mathrm{wt} . \%$ MWCNT with $0.5 \mathrm{wt} . \%$ GO gives the best results, reaching V0.

These results confirm that the hybridization of GO, MWCNT, and nanoclay gives not only high mechanical properties but also good flame-retardant properties. This result will promise in the future a potential hybrid material with high fire resistance and good mechanical properties. However, in order to be able to apply it in industry, it is necessary to continue to research on different plastic substrates at different combination ratios to increase the application level in a wide range.

The surface SEM images of the materials after the UL 94 $\mathrm{V}$ combustion test are shown in Figure 3. As shown in Figures 3(a)-3(c), the surface structure of the material after burning did not appear to have cracks. Structural damage is not observed. Nanoadmixtures (nanoclay, MWCNT) formed a nanocoating on the surface of GO to effectively block oxygen transport and thereby reduce the decomposition reactions that occurred. GO shows excellent flame resistance in nanohybrid coatings. The flame-retardant coal produced by the nanoadmixture covered on the GO surface can prevent flammable volatiles from diffusing to the surface flame and thus shield the polymer chains from heat and oxygen effectively. Figures 3(a)-3(b) show spherical porous structures on the surface after burning. Unfortunately, such a porous structure after combustion will not limit heat and oxygen attack in internal molecules thereby causing structural damage. A nanoclay/MWCNT/GO coating is formed to protect combustible materials from flame penetration. This coating acts as an effective barrier to effectively inhibit

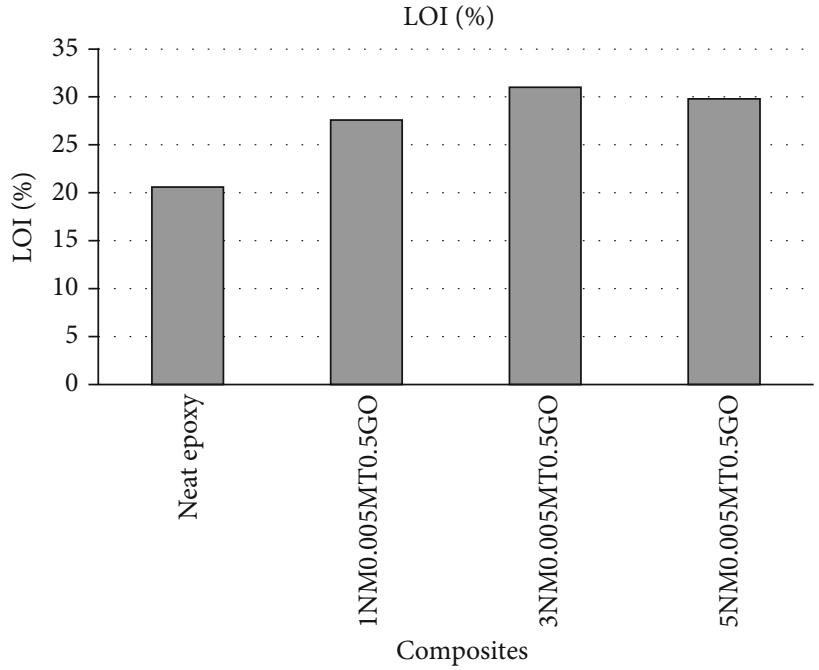

FIgURe 2: LOI values of epoxy composite.

TABLE 2: Combustion parameters of epoxy nanocomposites.

\begin{tabular}{lcccc}
\hline Samples & & & UL 94 V & \\
& $t_{1}(\mathrm{~s})$ & $t_{2}(\mathrm{~s})$ & Burning grade & Dripping \\
\hline Neat epoxy & - & - & - & - \\
1NM0.005MT0.5GO & 18 & 16 & V-1 & No \\
3NM0.005MT0.5GO & 8.7 & 7.5 & V0 & No \\
5NM0.005MT0.5GO & 15 & 12 & V1 & No \\
\hline
\end{tabular}

heat and oxygen; and, therefore, the flame resistance is greatly improved when complete. Figure 3(c) shows that the surface of the material after combustion is smooth; the alignment on the interface between the porous structure and the rest of the material is showing the solid structure, after burning confirm that the topology can be kept well. The addition of nanoclay, MWCNT, and GO to the epoxy resin matrix improved the fire resistance of the material. The best flame retardancy was at $3 \mathrm{wt} . \%$ nanoclay, 0.05 wt.\% MWCNT, and 0.5 wt.\% GO.

3.3. Morphology. The hybrid efficiency of nanoclay and MWCNT and GO is basically determined by the degree of dispersion as well as the interaction and interface binding with the epoxy-based resin. Therefore, morphometric analysis is very important to determine the dispersion and interaction of nanoadmixtures and epoxy matrix.

The results of the structural morphology analysis (SEM) of the hybrid materials are presented in Figures 4 and 5. As discussed previously, the mechanical and flame-retardant properties of the hybrid materials, especially the hybrid materials, were at the combined ratio: $0.5 \mathrm{wt} . \%$ GO and 0.05 wt.\% MWCNT with 3 wt.\% nanoclay.

From the results of Figure 4, it can be observed that at the material fracture surface, individual MWCNT nanoreinforced materials are protruding from the interface between nanoclay, GO, and epoxy (white and red arrows, see Figure 4). Thus, there was a synergistic effect of the 


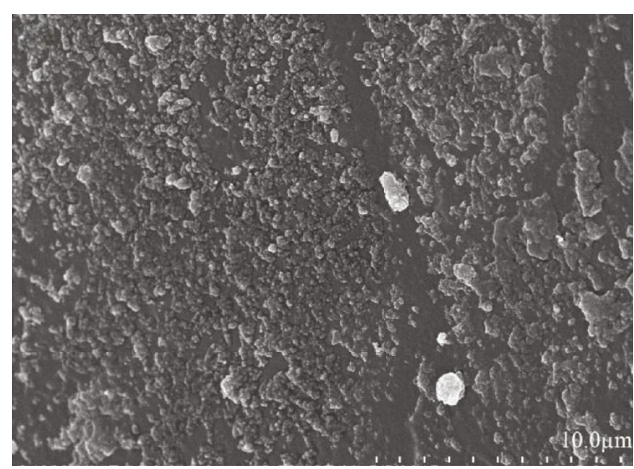

(a)

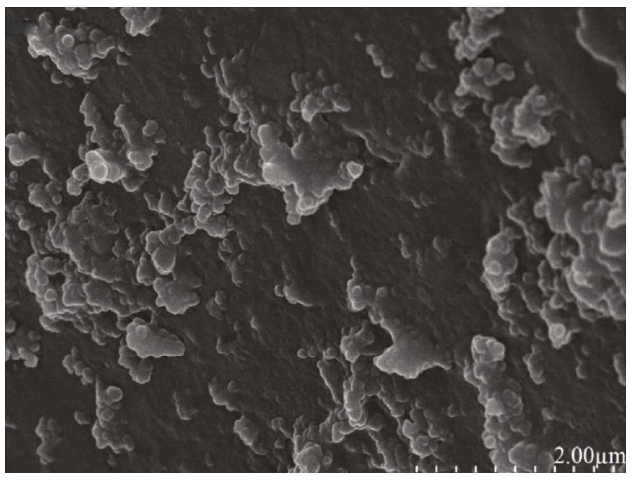

(c)

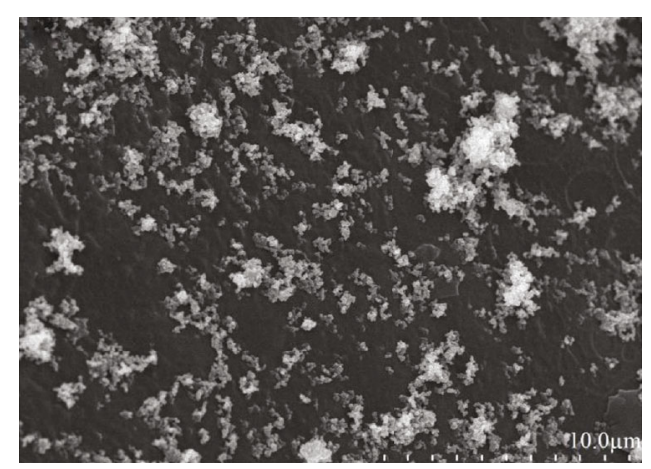

(b)

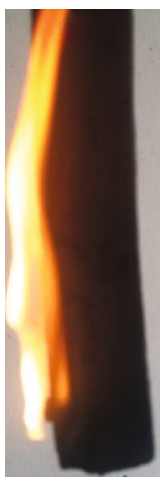

(d)

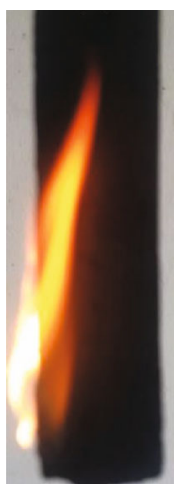

(e)

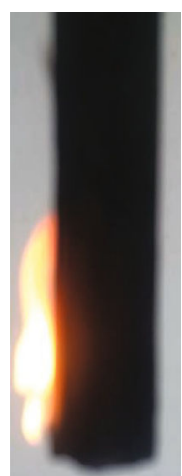

(f)

FIGURE 3: Flame-retardant mechanism analysis. SEM image of material surface after burning according to the UL $94 \mathrm{~V}$ method: (a, d) 1NM0.005MT0.5GO, (b, e) 5NM0.005MT0.5GO, and (c, f) 3NM0.005MT0.5GO.

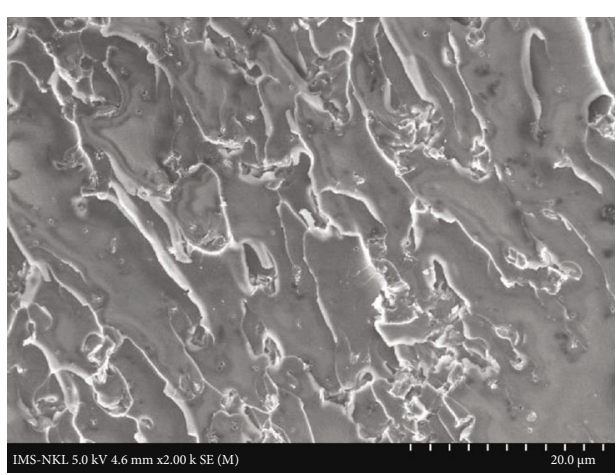

(a) $\times 2.00 \mathrm{k}$

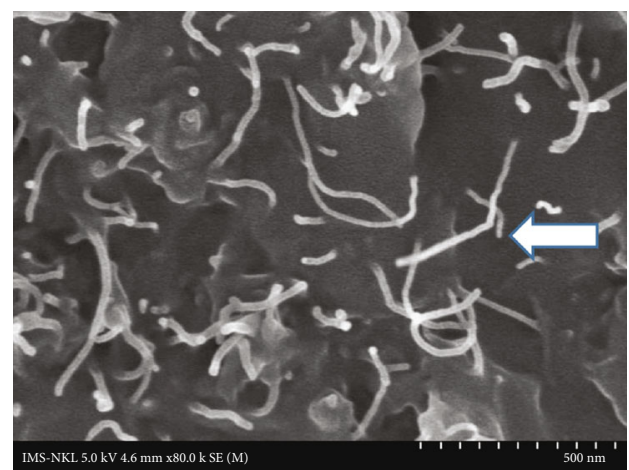

(c) $\times 80.0 \mathrm{k}$

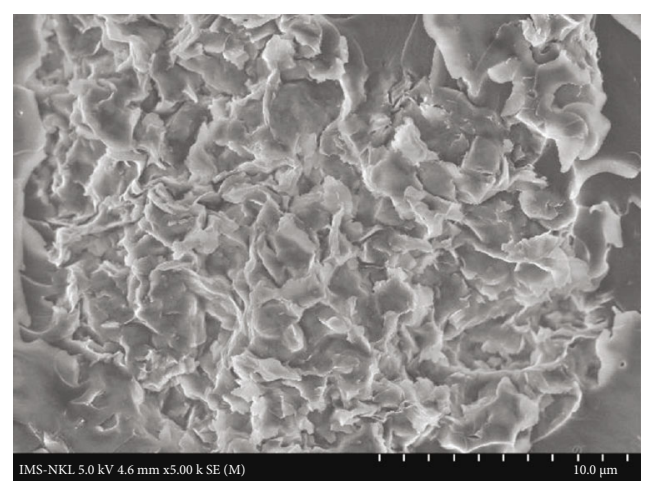

(b) $\times 5.00 \mathrm{k}$

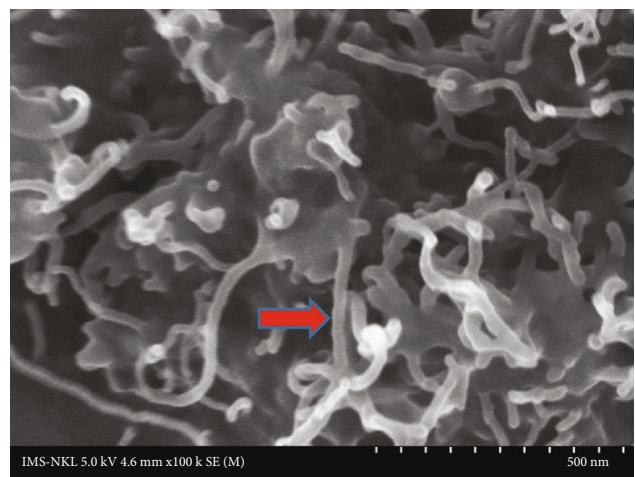

(d) $\times 100 \mathrm{k}$

Figure 4: SEM images of the hybrid GO (0.05 wt.\%), MWCNT (0.05 wt.\%), and nanoclay (3 wt.\%) at different resolutions. 


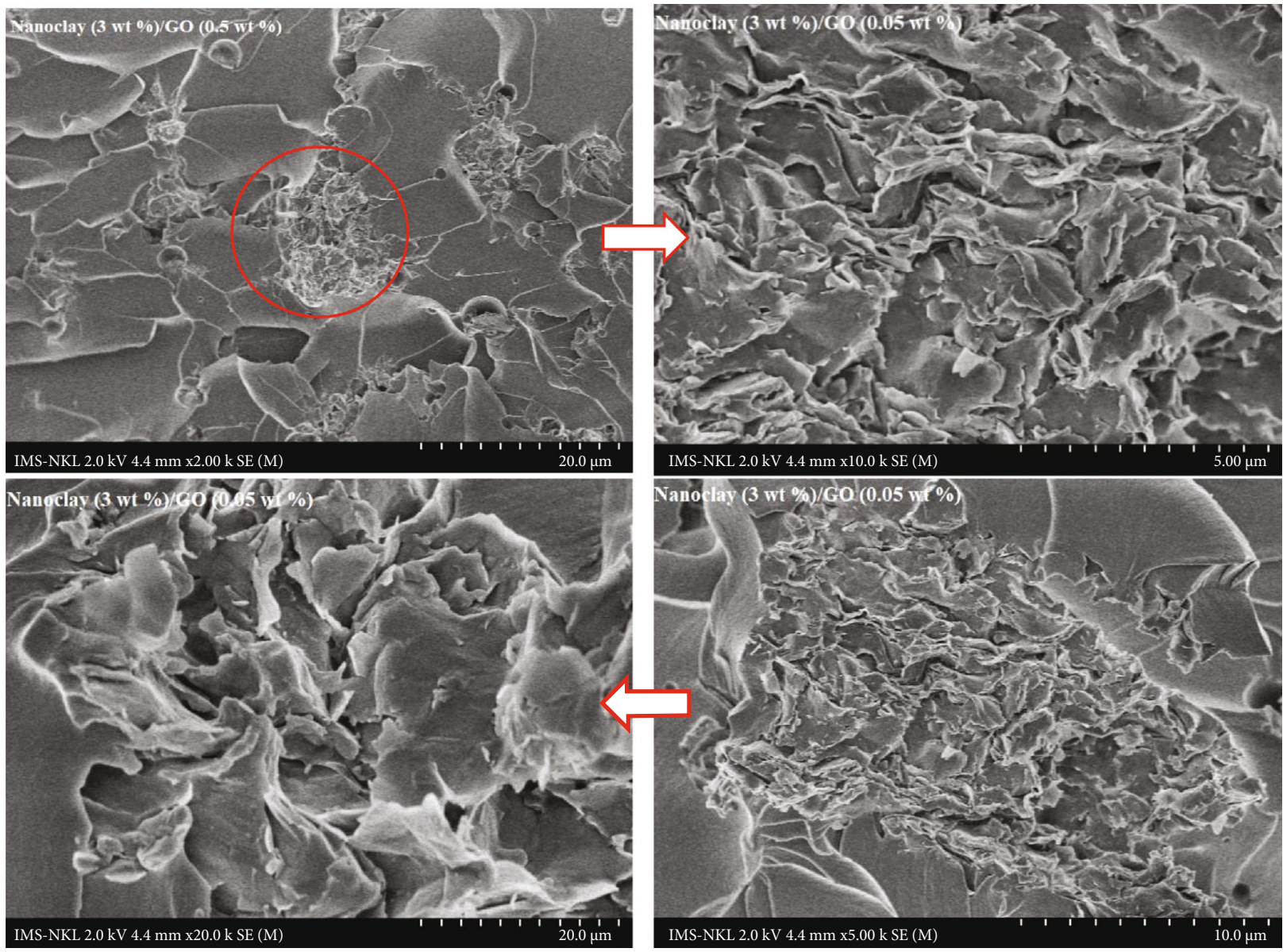

FIGURE 5: SEM images of the hybrid GO (0.05 wt.\%) and nanoclay (3 wt.\%) at different resolutions, with different resolutions: $2.00 \mathrm{k}, 5.00 \mathrm{k}$, $10.0 \mathrm{k}$, and $20.0 \mathrm{k}$.

nanoparticles. This finding supports the results obtained from the mechanical strength and flammability testing discussed before.

On the other hand, Figures 4 and 5 show a clean fault surface with sharp edges. Figure 5 shows the dispersion of nanoclay (red circle in Figure 5) and GO (colored arrow in white Figure 5). Figure 4(d) at $\times 100 \mathrm{k}$ magnification shows the adhesion between MWCNT/nanoclay/GO and the epoxy matrix as all nanotubes including the agglomerated MWCNTs which are well covered by the polymeric substrate, resulting in mechanical outstanding efficiency.

3.4. Results of Infrared Spectroscopy (IR) Measurement. The results of the infrared spectra of the materials are shown in Figure 6. The valency of the $\mathrm{O}-\mathrm{H}$ group from $3507.92 \mathrm{~cm}^{-1}$ is shifted down to $3376.73 \mathrm{~cm}^{-1}$, respectively, 3395.09 . The legs of the absorption fringes, in turn, tend to be wider and less intense. The $\mathrm{C}-\mathrm{H}$ valence oscillation of the $\mathrm{CH}_{2}$ group and the aromatic ring of the absorption band are narrowed and shortened.

On the FTIR spectrum, it was found that the analysis was obtained from the infrared spectrum of epoxy/GO/MWCNT/nanoclay films with a wavelength range of $400-4000 \mathrm{~cm}^{-1}$. On the infrared spectrum, the absorption band is characteristic for the following: the valence oscilla-

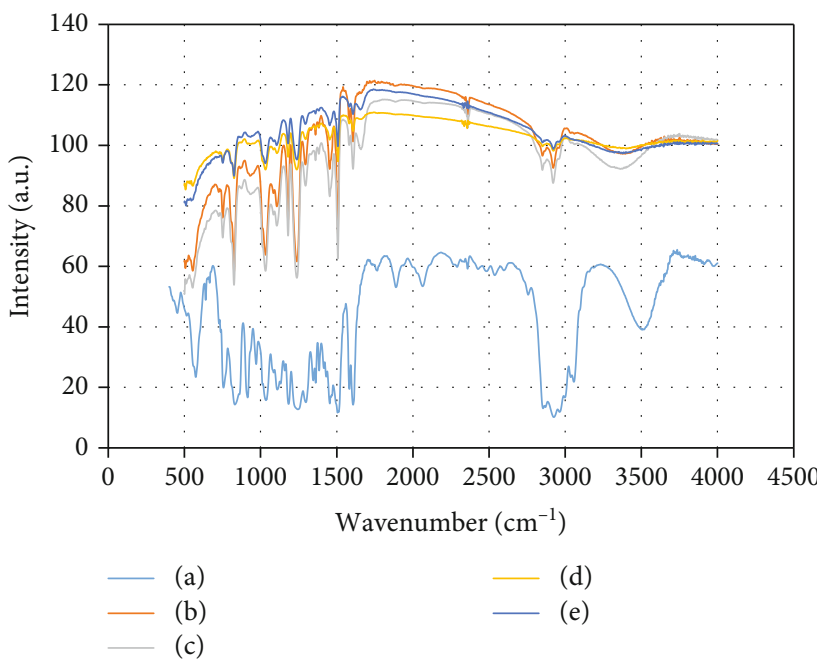

Figure 6: Infrared spectrum of epoxy resin, epoxy/0.5 wt.\%GO, epoxy $/ 0.5$ wt. $\%$, and GO/0.05 wt.\% MWCNT/nanoclay composite: (a) neat epoxy, (b) MWCNT/nanoclay/GO/epoxy, (c) nanoclay/GO/epoxy, (d) MWCNT/GO/epoxy, and (e) GO/epoxy.

tion of the $-\mathrm{OH}$ group is at about $3395 \mathrm{~cm}^{-1}$, the $\mathrm{C}=\mathrm{C}$ group is at about $1606 \mathrm{~cm}^{-1}$, and the $\mathrm{C}-\mathrm{O}$ bond is at $1032 \mathrm{~cm}^{-1}$. Besides, there is an absorption band characteristic for the 
$\mathrm{CH}_{2}$ group which is asymmetric and symmetrical at about 2921.39 and $2850.07 \mathrm{~cm}^{-1}$. Angular strain oscillation of Si$\mathrm{O}-\mathrm{Si}$ bond is at about $554.72 \mathrm{~cm}^{-1}$.

\section{Conclusions}

This study investigates how the combination and hybridization of nanoclay, MWCNT, and graphene oxide (GO) affect the mechanical properties and flame retardancy on epoxy resins. It can be concluded that the hybridization between 3 wt. $\%$ nanoclay and 0.05 wt.\% MWCNT and 0.5 wt.\% graphene oxide on epoxy resin substrate produces a hybrid material with outstanding mechanical and flame-retardant properties. The mechanical properties and fire resistance results demonstrated that the combined use of MWCNT, nanoclay, and $\mathrm{GO}$ at an appropriate ratio will produce an enhanced effect, synergizing good properties.

\section{Data Availability}

The data used to support the findings of this study are included within the article.

\section{Conflicts of Interest}

The authors declare that there is no conflict of interest regarding the publication of this paper.

\section{Acknowledgments}

The authors wish to thank the Faculty of Chemical Technology, Hanoi University of Industry, Vietnam, for funding this work.

\section{References}

[1] M. H. M. Yazik, M. T. H. Sultan, N. Mazlan et al., "Effect of hybrid multi-walled carbon nanotube and montmorillonite nanoclay content on mechanical properties of shape memory epoxy nanocomposite," Journal of Materials Research and Technology, vol. 9, no. 3, pp. 6085-6100, 2020.

[2] T. A. Nguyen, Q. T. Nguyen, and T. P. Bach, "Mechanical properties and flame retardancy of epoxy resin/nanoclay/multiwalled carbon nanotube nanocomposites," Journal of Chemistry, vol. 2019, Article ID 3105205, 9 pages, 2019.

[3] T. A. Nguyen, "Mechanical and flame-retardant properties of nanocomposite based on epoxy resin combined with epoxidized linseed oil, which has the presence of nanoclay and MWCNTs," Journal of Chemistry, vol. 2020, 8 pages, 2020.

[4] T. A. Nguyen and T. M. H. Pham, "Study on the properties of epoxy composites using fly ash as an additive in the presence of nanoclay: mechanical properties, flame retardants, and dielectric properties," Journal of Chemistry, vol. 2020, 11 pages, 2020.

[5] T. A. Nguyen, Q. T. Nguyen, X. C. Nguyen, and V. H. Nguyen, "Study on fire resistance ability and mechanical properties of composites based on Epikote 240 epoxy resin and thermoelectric fly ash: an ecofriendly additive," Journal of Chemistry, vol. 2019, Article ID 2635231, 8 pages, 2019.

[6] T. A. Nguyen, "Effects of the amount of fly ash modified by stearic acid compound on mechanical properties, flame retardant ability, and structure of the composites," International Journal of Chemical Engineering, vol. 2020, 6 pages, 2020.
[7] S. Ran, F. Fang, Z. Guo et al., "Synthesis of decorated graphene with $\mathrm{P}, \mathrm{N}$-containing compounds and its flame retardancy and smoke suppression effects on polylactic acid," Composites Part B: Engineering, vol. 170, pp. 41-50, 2019.

[8] B. Dittrich, K.-A. Wartig, D. Hofmann, R. Mülhaupt, and B. Schartel, "Flame retardancy through carbon nanomaterials: carbon black, multiwall nanotubes, expanded graphite, multilayer graphene and graphene in polypropylene," Polymer Degradation and Stability, vol. 98, no. 8, pp. 1495-1505, 2013.

[9] Y. R. Lee, S. C. Kim, H.-i. Lee et al., "Graphite oxides as effective fire retardants of epoxy resin," Macromolecular Research, vol. 19, no. 1, pp. 66-71, 2011.

[10] W. Wu, Y. Xu, H. Wu et al., "Synthesis of modified graphene oxide and its improvement on flame retardancy of epoxy resin," Journal of Applied Polymer Science, vol. 2019, pp. 1-11, 2019.

[11] A. L. Higginbotham, J. R. Lomeda, A. B. Morgan, and J. M. Tour, "Graphite oxide flame-retardant polymer nanocomposites," ACS applied materials \& interfaces, vol. 1, no. 10, pp. 2256-2261, 2009.

[12] T. A. Nguyen and Q. T. Nguyen, "Study on synergies of fly ash with multiwall carbon nanotubes in manufacturing fire retardant epoxy nanocomposite," Journal of Chemistry, vol. 2020, 9 pages, 2020.

[13] Y.-M. Jen, J.-C. Huang, and K.-Y. Zheng, "Synergistic effect of multi-walled carbon nanotubes and graphene nanoplatelets on the monotonic and fatigue properties of uncracked and cracked epoxy composites," Polymers, vol. 12, no. 1895, pp. 1-23, 2020.

[14] D. A. Hawkins Jr. and A. Haque, "Fracture toughness of carbon-graphene/epoxy hybrid nanocomposites," Procedia Engineering, vol. 90, pp. 176-181, 2014.

[15] N. V. Medhekar, A. Ramasubramaniam, R. S. Ruoff, and V. B. Shenoy, "Hydrogen bondnetworks in graphene oxides nanocomposites paper: structural and mechanical properties," American Chemical Society, vol. 4, pp. 2300-2306, 2010.

[16] J. K. Paduvilan, P. Velayudhan, A. Amanulla, H. J. Maria, A. Saiter-Fourcin, and S. Thomas, "Assessment of graphene oxide and nanoclay based hybrid filler in chlorobutyl-natural rubber blend for advanced gas barrier applications," Nanomaterials, vol. 11, no. 1098, pp. 1-14, 2021.

[17] S. Li, Z. Yang, J. Xu, J. Xie, and J. Sun, "Synthesis of exfoliated graphene-montmorillonite hybrids as the fillers for epoxy composites," Journal of Composite Materials, vol. 53, no. 3, pp. 315-326, 2019.

[18] M. Nuruddin, R. Gupta, A. Tcherbi-Narteh, M. Hosur, and S. Jeelani, "Synergistic effect of graphene nanoplatelets and nanoclay on epoxy polymer nanocomposites," Advanced Materials Research, vol. 1119, pp. 155-159, 2015.

[19] M. Abdolmaleki, M. Ganjaee Sari, M. Rostami, and B. Ramezanzadeh, "Graphene oxide nanoflakes as an efficient dispersing agent for nanoclay lamellae in an epoxy-phenolic nanocomposite coating: mechanistic approach," Composites Science and Technology, vol. 184, article 107879, 2019.

[20] F. Gauvin, P. Cousin, and M. Robert, "Effect of modified graphene oxide on the mechanical, thermal, and barrier properties of vinylester," Journal of Composite Materials, vol. 52, no. 28, pp. 3853-3864, 2018.

[21] D. Zhuo, R. Wang, L. Wu et al., "Flame retardancy effects of graphene nanoplatelet/carbon nanotube hybrid membranes on carbon fiber reinforced epoxy composites," Journal of Nanomaterials, vol. 2013, 7 pages, 2013. 